\title{
Antiviral Resistance and Correlates of Virologic Failure in the first Cohort of HIV-Infected Children Gaining Access to Structured Antiretroviral Therapy in Lima, Peru: A Cross-Sectional Analysis
}

Barbara A Rath ${ }^{1,2,8^{*}}$, Max von Kleist ${ }^{3}$, Maria E Castillo ${ }^{4,9}$, Lenka Kolevic ${ }^{4}$, Patricia Caballero ${ }^{5}$, Giselle Soto-Castellares ${ }^{6}$, Angela M Amedee ${ }^{7}$, James E Robinson ${ }^{2}$, David K Katzenstein ${ }^{8}$, Russell B Van Dyke ${ }^{2}$ and Richard A Oberhelman ${ }^{2}$

\begin{abstract}
Background: The impact of extended use of ART in developing countries has been enormous. A thorough understanding of all factors contributing to the success of antiretroviral therapy is required. The current study aims to investigate the value of cross-sectional drug resistance monitoring using DNA and RNA oligonucleotide ligation assays (OLA) in treatment cohorts in low-resource settings. The study was conducted in the first cohort of children gaining access to structured ART in Peru.

Methods: Between 2002-5, 46 eligible children started the standard regimen of AZT, 3TC and NFV Patients had a median age of 5.6 years (range: 0.7-14y), a median viral load of 1.7.10 RNA/ml (range: 2.1 $10^{3}-1.2 \cdot 10^{6}$ ), and a median CD4-count of 232 cells/ $\mathrm{LL}$ (range: 1-1591). Of these, 20 patients were classified as CDC clinical category C and 31/46 as CDC immune category 3. At the time of cross-sectional analysis in 2005, adherence questionnaires were administered. DNA OLAs and RNA OLAs were performed from frozen PBMC and plasma, RNA genotyping from dried blood spots.

Results: During the first year of ART, $44 \%$ of children experienced virologic failure, with an additional $9 \%$ failing by the end of the second year. Virologic failure was significantly associated with the number of resistance mutations detected by DNA-OLA ( $p<0.001$ ) during cross-sectional analysis, but also with low immunologic CDC-scores at baseline $(p<0.001)$. Children who had been exposed to unsupervised short-term antiretrovirals before starting structured ART showed significantly higher numbers of resistance mutations by DNA-OLA ( $p=0.01$ ). Detection of M184V (3TC resistance) by RNA-OLA and DNA-OLA demonstrated a sensitivity of 0.93 and 0.86 and specificity of 0.67 and 0.7 , respectively, for the identification of virologic failure. The RT mutations N88D and L90M (NFV resistance) detected by DNA-OLA correlated with virologic failure, whereas mutations at RT position 215 (AZT resistance) were not associated with virologic failure.

Conclusions: Advanced immunosuppression at baseline and previous exposures to unsupervised brief cycles of ART significantly impaired treatment outcomes at a time when structured ART was finally introduced in his cohort. Brief maternal exposures to with AZT +/- NVP for the prevention of mother-to-child transmission did not affect treatment outcomes in this group of children. DNA-OLA from frozen PBMC provided a highly specific tool to detect archived drug resistance. RNA consensus genotyping from dried blood spots and RNA-OLA from plasma consistently detected drug resistance mutations, but merely in association with virologic failure.
\end{abstract}

\footnotetext{
*Correspondence: barbara.rath@gmail.com

'Department of Pediatrics, Division of Pneumonology-Immunology, Charité

University Medical Center, Berlin, Germany

${ }^{2}$ Department of Pediatrics, Division of Infectious Diseases, Tulane University

Health Sciences Center, New Orleans, Louisiana, USA

Full list of author information is available at the end of the article
} 


\section{Background}

Antiretroviral therapy (ART) has, for the past years, increased the hope for survival of millions of people living with the human immunodeficiency virus (HIV) worldwide, adults as well as children. A clear survival advantage was achieved for HIV-infected patients with a dramatic decrease in new AIDS cases [1]. Immune reconstitution ensues when viral replication can be suppressed successfully over time [2].

Once a first-line regimen has failed however, the reasons for such failure may be complex, including malnutrition and co-morbidities leading to poor absorption of medications. Lack of economic resources and education may further complicate the already difficult adherence to complex medication schedules [3-11]. Some patients may have been pre-exposed to intermittent or erratic courses of antiretrovirals through aid programs, private activities and contacts abroad. HIV-infected children may have also been infected with a resistant maternal virus through mother-to-child transmission (MTCT) $[12,13]$. In resource-limited settings where medications for standard first-line ART medications are often purchased en bloc and large groups of patients are started on ART simultaneously, cross-sectional drug resistance testing may be particularly useful.

This study aims to test the value and feasibility of cross-sectional resistance testing as well as innovative tools to display disease progression or clinical/immunological improvement in the first cohort of children starting ART in Peru. With Global Fund support, structured ART first became available in August 2002 to a select group of HIV-infected children at the Instituto Nacional de Salud del Niño (INSN) in Lima, based on the criteria established by the Guideline for the Management of the HIV-Infected Child by the Peruvian Ministry of Health (MINSA) [14-17].

In contrast to a neonatal cohort starting ART several years later, the majority of patients in this first cohort at the INSN were school-age, had already progressed to AIDS when starting ART and were born before the broad introduction of prevention of mother-to-child transmission (pMTCT) programs in Peru [18]. Therefore, most patients were considered ART-naive prior to starting the Peruvian standard first-line regimen, consisting azidothymidine (AZT, $100 \mathrm{mg} / \mathrm{m}^{2}$ every 12 hours) with lamivudine (3TC, $4 \mathrm{mg} / \mathrm{Kg}$. every 12 hours) and nelfinavir (NFV, $25 \mathrm{mg} / \mathrm{Kg}$. every 8 hours) [17].

At the time of introduction of ART in Peru, access to drug resistance testing was still limited. To save cost, alternative testing methodologies and transportation modalities were sought, such as the Oligonucleotide Ligation Assay (OLA) [19-21] and filter cards for the transportation of blood samples as dried spots [22-26].

The aims of the study were:
1. To determine the prevalence of antiretroviral drug resistance in children with virologic failure versus no virologic failure.

2. To evaluate the sensitivity of the DNA-OLA from frozen peripheral blood mononuclear cells (PBMC) as compared to the OLA from virion RNA (plasma) and RNA consensus sequencing from dried blood spots.

3. To determine factors associated with virologic failure and drug resistance development.

4. To design a simple and integrative display of clinical/ immunological progression of HIV disease after ART initiation.

\section{Methods}

\section{Patient Population and Study Procedures}

From 2002-2005, study participants had undergone standard medical procedures and routine HIV medical care at the Infectious Diseases Service at the INSN. According to the MINSA Guideline for the Management of the HIVInfected Children, CD4+counts had been determined every 3 months, and viral load every 6 months at the Peruvian National Institutes of Health (Instituto Nacional del Salud, INS) [16]. Antiretroviral therapy for eligible patients was provided free of charge by the MINSA. Eligibility criteria for ART provided by the Peruvian Ministry of Health included: Established perinatal HIV infection ${ }^{a}$ and age $<18$ months, or age $>18$ months and CDC immune category 2 or 3 . Exceptions were planned for asymptomatic patients with a rapid decline in CD4+ or viral load $>100,000 \mathrm{cp} / \mathrm{ml}$ (or $>10,000-20,000$ in those $>$ 30 months) [16]. Ethics approval was obtained by the respective institutional review boards (IRB) in the US and Peru.

For the cross-sectional analysis in 2005, all eligible subjects undergoing ART according to the MINSA program who agreed to participate and whose parents/guardians had signed the informed consent, were included. Basic clinical and virologic parameters from the start of ART in the individual patient until the date of testing were extracted from routine medical records and laboratory reports (viral load and CD4 testing data). Additional parameters were obtained, such as CDC stage [27], opportunistic and other infections, medication and dosing information, and adverse events attributable to ART. A previously published standardized adherence questionnaire (PACTG P1042S) was used at the time of cross-sectional analysis to systematically measure adherence based on information provided by parents and caregivers [28,29].

At the time of the first regular follow-up visit after entry into the study, routine blood sampling was again performed at the INS. In addition, $5 \mathrm{ml}$ of citrated blood were collected from study participants for resistance testing. In addition, two Guthrie filter cards were collected with 4 capillary blood spots (finger prick) of $50 \mathrm{uL}$ each. 


\section{Virologic testing}

Ficoll-Hypaque centrifugation and separation of the citrated blood was performed at the PRISMA laboratory in Lima. Plasma and PBMC were immediately stored separately at $-20 \mathrm{C}$ and shipped on dry ice to the Tulane and LSU PACTU laboratory for RNA and DNA extraction. Viral loads in plasma were quantified by real-time RT-PCR as described [30].

The OLA was conducted according to the NIH protocol for mutations at HIV-1B protease positions D30N, I50V, V82A, V82S, V82T, I84V, N88D, and L90M as well as reverse transcriptase positions K103N, Y181C, K65R, T215F, T215Y, M184V, and Q151M [21,31]. Dried Blood Spots (DBS) collected on Guthrie cards were stored at room temperature to be shipped to the Stanford Center for AIDS Research for consensus RNA sequencing [32].

\section{Definition of virologic failure}

For the purposes of the study, virologic failure was defined by two or more consecutive HIV RNA measurements above the detection limit $(400 \mathrm{cp} / \mathrm{ml}), 4-6$ months after the initiation of ART therapy in patients where $\geq 2$ viral load measurements were available. In patients P016T, P021T, P041T, P053T and P057T only two viral load measurements were available in total. These patients all showed signs of virologic failure indicated by HIV RNA measurements $>400 \mathrm{cp} / \mathrm{ml}>10$ months after treatment initiation.

\section{Sample size calculation}

We assessed the population size $N$ needed for assessing differences in resistance development between patients failing ART and those successfully treated.

We assumed that $50 \%$ of patients would eventually fail ART $P$ (failure) $=0.5$ and that those failing ART would with $90 \%$ probability develop drug resistance $P$ (res. $\mid$ failure $)=0.9$.

Conversely, successfully treated patients may with $10 \%$ probability develop resistance $P$ (res.|sucess) $=0.1$. We can therefore compute the expected number of patients with failure and resistance $\mathrm{a}=P($ res. |failure $) \bullet P($ failure $) \bullet N$, with failure and no resistance $b=(1-P($ res. $\mid$ failure $)) \bullet P$ (failure) $\bullet N$, with no failure and resistance $c=P($ res. | success $) \bullet(1-P$ (failure) $) \bullet N$ and with no failure and no resistance $d=(1-P($ res. $\mid$ success $)) \bullet 1-P($ failure $)) \bullet N$.

According to Fisher's exact statistics $p=\frac{\left(\begin{array}{c}a+b \\ a\end{array}\right)\left(\begin{array}{c}c+d \\ c\end{array}\right)}{\left(\begin{array}{c}N \\ a+c\end{array}\right)}$

for the underlying contingency table, we could show significance at the $5 \%$ level $(p \leq 0.05)$ for a sample size of $N=12$. For values $P($ res. $\mid$ failure $)=0.8, P($ res. $\mid$ failure $)=0.7$ and $P($ res. $\mid$ failure $)=(1-P($ res. $\mid$ sucess $))$ population sizes of $N=12$ and $N=22$ would be required.

\section{Rates of clinical/immunological progression}

For the purpose of this analysis, CDC categories were applied in a novel way, assigning new $\mathrm{CDC}$ categories at each assessment time point ignoring previous $\mathrm{CDC}$ scores.

The rates of clinical and immunological progression $r_{\mathrm{C}}$ and $r_{I}$ respectively (average change of CDC score per year throughout the study population) were computed with the following formula

$$
\left(\begin{array}{c}
r_{I} \\
r_{C}
\end{array}\right)=\left(\begin{array}{c}
\sum_{m_{I}} F_{m, I} \cdot m_{I} \\
\sum_{m_{C}} F_{m, C} \cdot m_{C}
\end{array}\right) \text {, where } m_{I} \text { and } m_{C} \text { denote }
$$

the magnitude (number of scores) of change observed and $F_{m, I}$ and $F_{m, C}$ the fractions that have changed by that magnitude within a certain time interval. For our evaluation, we computed the rates of immunological and clinical progressionfrom enrolment throughout years 1, 2 and and beyond $(>=3)$.

\section{Assessment of the nutritional status using standard scores (Z-scores)}

Malnutrition in the study population was assessed in terms of standard scores (z-scores) of child weight at enrolment in relation to the WHO reference weight [33]. The standard scores are defined by $z=\frac{x-\mu}{\sigma}$, where $x$ represents the child's weight and $\mu$ and $\sigma$ denote the average weight within the child's age category based on the WHO reference and standard deviation, respectively [33]. A standard score of $\mathrm{z}=-2$ therefore denotes that the child's weight is two standard deviations below average (i.e. $x=\mu-2 \sigma$ ).

\section{Results}

\section{Demographics}

A total number of 46 children were enrolled between September 2002 and March 2005. Median age at enrolment was 5.6 years (range: $0.7-14 y$ ). The median viral load at enrolment was $1.7 \cdot 10^{5} \mathrm{RNA} / \mathrm{ml}$ (range: $2.1 \cdot 10^{3}-1.2 \cdot 10^{6}$ ) and the median CD4-count was 232 cells/ $\mu \mathrm{L}$ (range: 11591). Notably, five children had CD4 counts below 10 cells $/ \mu \mathrm{L}$. The median weight at enrolment was $18 \mathrm{~kg}$ (range: 5.5-45). Notably, 43/46 (93\%) had negative z-scores for child weight compared to the WHO reference corresponding age group [33], indicating evidence of malnutrition in this cohort. The median z-score was -2 (range: -4 to 0). CDC clinical categories (according to the 1994 Revised Classification System for HIV Infection in Children [27]) were attributed to each patient at baseline and again with each follow-up visit. Seven children were classified as clinical category $\mathrm{N}$ (not symptomatic), 4 children fell into clinical category A (mildly symptomatic), 15 were in category B (moderately symptomatic) and 20 were in category $\mathrm{C}$ (severely symptomatic). Notably, eight children 
(17\%) were co-infected with active tuberculosis at enrolment. Children were also staged with respect to immune categories, according to the 1994 CDC classification system [27]. Four children were in category 1, 11 were in category 2 , and 31 fell into category 3. Basic demographic characteristics are displayed in Table 1.

Vertical HIV transmission was the mode of infection for all but two children, who were infected by blood transfusion. Seven mothers had received antiretroviral prophylaxis with AZT +/- NVP for the prevention of mother-to-child transmission (pMTCT). Three children had been exposed to postnatal AZT for pMTCT (P019T, P020T, P028T). Four children had been exposed to unsupervised ART prior to enrolment: two children (P057T, P067T) received 3TC+AZT prior to enrolment. One child (P067T) continued NFV+3TC+AZT without any gap, while P053T and P016T had received NFV $+3 \mathrm{TC}+\mathrm{AZT}$ prior to initiation of the program. One child P016T continued with only a few weeks interruption, whereas for P053T there was a gap of one year between his prior ART medication and ART medication provided through this program. Throughout the study period, standard treatment was modified in five children (P007T, P011T, P019T, P031T and P057T). In these children, one component of their ART regimen was substituted respectively: AZT was replaced by stavudine $(\mathrm{d} 4 \mathrm{~T})$ in P011T and P031T, 3TC was replaced by didanosine (DDI) in P057T, and NFV was replaced by nevirapine (NVP) in P007T and P019T.

\section{Viral dynamics and virologic failure rates}

The central tendency of viral dynamics is shown in Figure 1A. The corresponding viral load measurements for all children are displayed in Additional File 1. Virologic failure was defined by two or more measurements demonstrating $>400$ copies/ml RNA after 16 weeks of treatment (see filled squares in Additional file 1). The cumulative probability of virologic failure is shown in Figure 1B.

As can be seen, $44 \%$ of children experienced virologic failure during the first year of ART, half of the children failed before the end of the second year of ART. By the end of the study, $60 \pm 16 \%$ had experienced virologic failure.

Both patients who had been infected by blood transfusion $(2 / 2)$ and all children with previous ART exposure (4/4) eventually experienced viral failure. None of the 7 children whose mothers had received pMTCT prophylaxis with AZT +/- NVP (0/7) and none of the children who had received post-natal AZT prophylaxis for pMTCT (0/3) experienced virologic failure.

Children who were younger at entry were slightly more likely to fail ART ( $p=0.06$ by Wilcoxon rank sum test). Virologic failure was significantly associated with the immunologic CDC-score at baseline (i.e. when starting structured ART; $\mathrm{p}<0.001$ by cross-tab $\chi^{2}$ test), with severely immunosuppressed patients being most likely to fail ART.

In contrast, the CDC clinical category at baseline was not predictive of virologic failure during subsequent ART. Children who had reported missing $>50 \%$ of doses (according to the adherence questionnaire administered) were also

Table 1 Basic Characteristics of Study Participants

\begin{tabular}{|c|c|c|c|}
\hline & All & With subseq. virol. failure & Without subseq. virol. failure \\
\hline & $n=46$ & $n=26$ & $n=20$ \\
\hline Gender (male n) & 27 & 16 & 11 \\
\hline Age (years) & $5.6(0.2 ; 14)$ & $5.0(0.67 ; 13.9)$ & $6.5(0.7 ; 13.8)$ \\
\hline Weight below WHO child reference (n) [33] & 43 & 24 & 19 \\
\hline Weight median z-score (range) & $-2.0(-4 ; 0)$ & $-2.5(-4 ; 0)$ & $-1(-4 ; 1)$ \\
\hline Baseline viral load (RNA/ml) & $1.7 \mathrm{e} 5(2.1 \mathrm{e} 3 ; 1.2 \mathrm{e} 6)$ & $2.1 \mathrm{e} 5(2.4 \mathrm{e} 4 ; 1.1 \mathrm{e} 6)$ & $8.4 \mathrm{e} 5(2.1 \mathrm{e} 3 ; 1.2 \mathrm{e} 6)$ \\
\hline CD4 count (cells/ $\mu \mathrm{L})$ & $232(1 ; 1519)$ & $154(1 ; 1591)$ & $381(2 ; 870)$ \\
\hline Tubercoulosis coinfection (n) & 8 & 3 & 5 \\
\hline \multicolumn{4}{|l|}{ Clinical CDC stage } \\
\hline N (not symptomatic) & 7 & 5 & 2 \\
\hline A (mildly symptomatic) & 4 & 3 & 1 \\
\hline B (moderately symptomatic) & 15 & 7 & 8 \\
\hline C (severely symptomatic) & 20 & 11 & 9 \\
\hline \multicolumn{4}{|l|}{ Immunological CDC stage } \\
\hline 1 & 4 & 1 & 3 \\
\hline 2 & 11 & 1 & 10 \\
\hline 3 & 31 & 24 & 7 \\
\hline
\end{tabular}

Table 1: Demographic characteristics and baseline disease status of study participants. 
more likely to experience virologic failure ( $\mathrm{p}=0.05$; crosstab $x^{2}$ test).

\section{Rates of immunologic \& clinical progression and child growth}

Neither immunologic CDC classification, nor clinical CDC classification at enrolment were correlated with the age of the children (but with the time between infection and start of therapy, $\mathrm{p}=0.39$ and $\mathrm{p}=0.83$; test for nonzero correlation).

Study participants were classified in terms of CDC clinical and immune categories at enrolment, during year 1 , during year 2, and after year 2, as shown in Figures 2A-D.

It can be seen in Figure $2 \mathrm{~A}$ that at the time of enrolment, that the majority of study participants are clustered in the lower right corner (intensity of shading \& percentages shown in the respective fields), which represents immunologic suppression (high immunologic CDC scores) and numerous opportunistic infections (immunologic scores ' $\mathrm{B}$ ' \& ' $C$ '). During year 1 after the onset of treatment (Figure 2B) the study participants' scores are distributed almost equally throughout the space defined by the respective CDC clinical and immunologic classifiers. During year 2 after treatment initiation, most of the study participants showed evidence of immunologic recovery and an overall decrease in the number of clinical signs of HIV/ AIDS, such as opportunistic infections (increasing percentages are found in the upper left corner in Figure 2C). After year two, a higher percentage of subjects are represented in the upper left corner of Figure 2D, while at the same time there is a slight regression to the right, indicating an overall clinical deterioration.

The overall rate of clinical/immunologic disease progression per treatment year is shown in Figures 3B-D: for the first year after enrolment (panel B), for the second year after enrolment (panel C), and for the time thereafter (panel D). It can be seen that antiviral treatment had a very positive effect on both immunologic and clinical parameters during the first year after ART initiation as well as during the subsequent year (the blue arrow pointing towards the upperleft in Figures $3 \mathrm{~B}$ and $\mathrm{C}$ ). The rate of improvement was -0.4 immunologic stages and -0.77 clinical stages during the first year after treatment initiation and -0.65 immunologic and -0.61 clinical stages from year 1 to year 2 .

Immunologic improvement was minimal during year three ( -0.1 stages), whereas the clinical status of the study participants worsened slightly by 0.16 stages on average (the blue arrow pointing towards the upper-right in Figure 3D). The overall changes during year three are very small. Whether these minor changes are also observable in larger cohorts, or whether they indicate a stabilization of immunologic and clinical progression warrants further investigation.

The immunologic CDC-scores at the time of final assessment were significantly correlated with virologic failure ( $\mathrm{p}<0.01$; cross-tab $\chi^{2}$ test), with patients failing therapy showing higher scores (i.e. being more severely compromised immunologically), while the final clinical CDCscores were not linked.

In summary, immunologic improvement became evident soon after initiation of ART and could be maintained
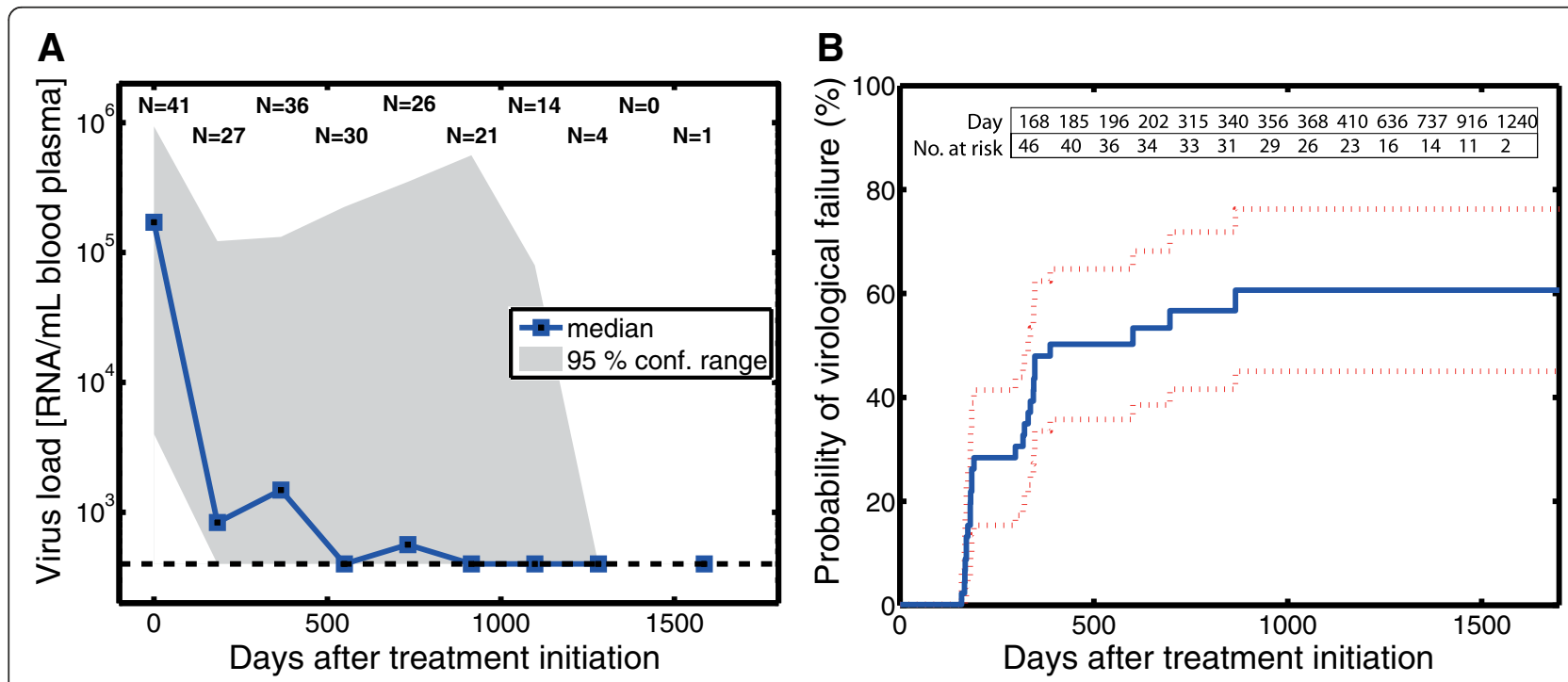

Figure 1 Viral Load Dynamics and Probability of Virologic Failure. A: Central tendency of the viral load dynamics after treatment initiation. The solid blue squares indicate the median viral load for all patients together with the confidence range spanned by the 5th and 95th percentiles (grey shading). The numbers at the top of the figure, e.g. $\mathrm{N}=30$, indicate the number of patients that gave rise to the estimates of the median viral load and its confidence area for the respective time points. B: Kaplan-Meier estimate of the cumulative probability of virologic failure after treatment initiation. 


\section{A}

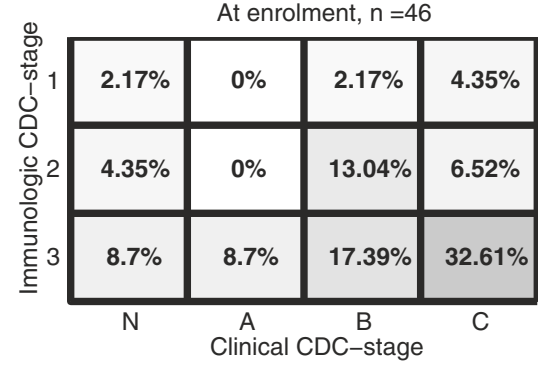

C

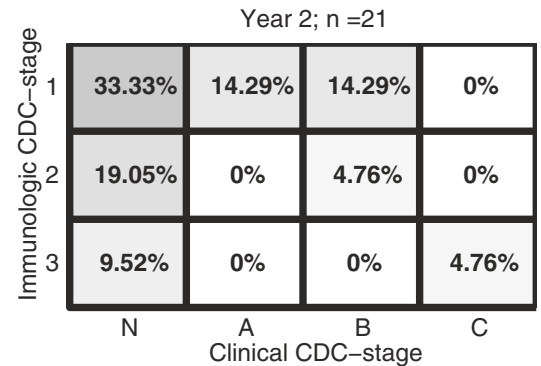

B

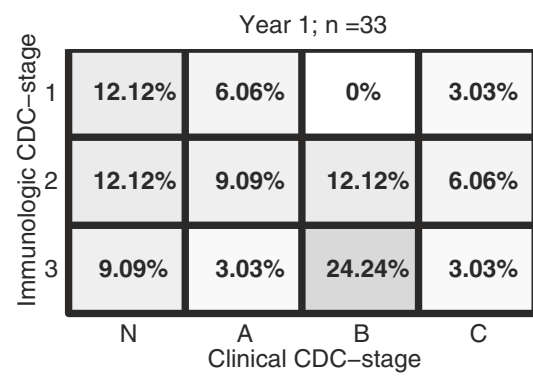

D

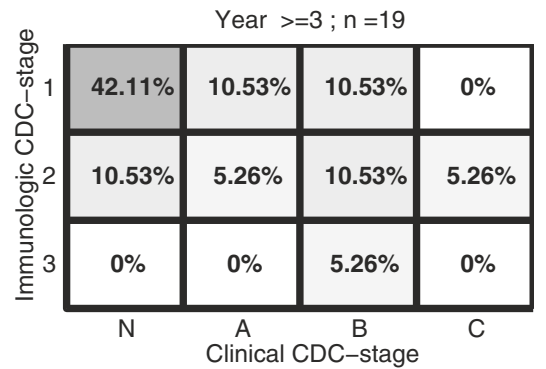

Figure 2 Classification of Study Participants. Immunologic and clinical classification of study participants at treatment initiation, throughout years 1 and 2 , and $\geq 3$ years after ART initiation. The numbers in the distinct fields and the intensity of the shading represent the percentage of individuals falling within the respective CDC classification. A: Classification at enrolment. B: Classification during year 1 after treatment initiation. C: Classification during year 2 after treatment initiation and $\mathbf{D}$ : Classification after year 2.
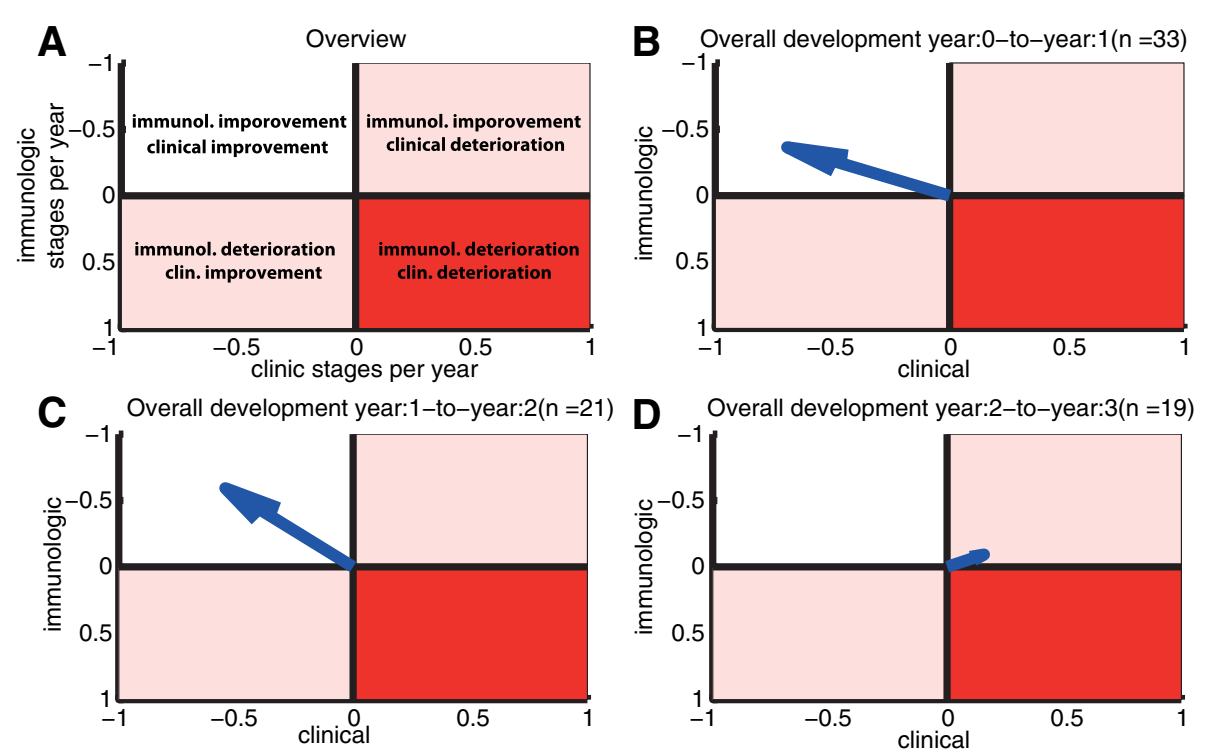

Figure 3 Disease Progression. Average rates of progression with respect to clinical and immune classifiers. A: The upper-left area indicates an overall improvement in terms of clinical and immune classifiers, whereas the upper-right area indicates immunological improvement but clinical deterioration. The lower-left area indicates immunological deterioration but clinical improvement, and the lower right area indicates deterioration with respect to both immunologic and clinical classifiers. B: The blue arrow indicates the overall rate of progression in the first year after treatment initiation (i.e. both clinical and immunologic parameters are improving). It was computed using the formula depicted in the Methods section ("Rates of clinical/immunological progression"). C: Overall rate of progression during the second year. D: Overall progression during the third year. 
in this cohort of first-line ART recipients, whereas the clinical improvement (with respect to CDC scores) seemed to lag behind, possibly due to the fairly advanced disease stages at baseline.

The median weight after 1, 2 and 3 years of treatment was $20 \mathrm{~kg}, 22.3 \mathrm{~kg}$ and $23 \mathrm{~kg}$, respectively. The median zscore was -1 . During the first year of ART, $72 \%$ of the children showed negative z-scores, 75\% in year 2 and $67 \%$ in/after year 3, which is a considerable improvement over child weight at enrolment, 93\% showed negative z-scores.

\section{Drug resistance testing}

On average, drug resistance testing was performed at 2.4 years after the initiation of structured ART. Prior to the cross-sectional analysis of this treatment cohort, drug resistance information had not been available to direct the choice of treatment regimens. In ART-failing patients, the vast majority of drug resistance tests (96\%) were performed at time points after virologic failure.

Samples for RNA consensus sequencing were transported as dried blood spots on Guthrie cards. RNA amplification for consensus genotyping was possible in 14/46 samples (including 3 samples with a viral load slightly below $400 \mathrm{cp} / \mathrm{ml}$ ), in 4 instances only the protease gene (PR) could be sequenced. All RNA consensus sequencing data is provided in Additional file 2. Overall, 70\% of HIV-1 RNA sequences were derived from individuals eventually failing ART. In the remaining cases, RNA could be amplified from two patients whose viral load had just dropped below $400 \mathrm{cp} / \mathrm{ml}$, one had repeated measurements slightly below the threshold.

Samples for DNA and RNA OLA testing were transported as frozen plasma and PBMC samples after FicollHypaque centrifugation and separation. Of these, RNAOLA testing was performed successfully in 20/46 (43\%), in one case only the protease mutations could be tested by RNA-OLA. All OLA data is provided in Additional File 3. As expected, the majority of samples yielding RNA-OLA results $(80 \%)$ were derived from patients with detectable viral loads. DNA-OLA testing however was successful in almost all patient samples (45/46, 98\%), of which $47 \%$ showed no evidence of virologic failure at the time of testing. Hence, DNA-OLA from frozen PBMC provided a sensitive tool for the cross-sectional assessment of archived drug resistance in this patient cohort. RNA consensus genotyping from dot blots and RNA-OLA from plasma virions yielded results predominantly in individuals with already established virologic failure (over-representing those with viral loads above the $400 \mathrm{cp} / \mathrm{ml}$ threshold).

\section{Drug resistance mutations}

The M184V reverse transcriptase mutation was detected in $80 \%$ of the sequenced RNA samples and tested positive in $74 \%$ and $47 \%$ by RNA-OLA and DNA-OLA, whereas thymidine associated mutations (TAMs: M41L, D67N, K70R, L210W, T215F/Y, K219Q/E [34]) were detected in $50 \%$ of sequenced viral RNA. Using RNA-OLA and DNAOLA, the T215Y and T215F mutations tested positive in $47 \%$ and $42 \%$, respectively.

The protease mutation D30N was detected in $43 \%$ of RNA genotyping samples and in $0 \%$ and $2 \%$ of available RNA- and DNA-OLA samples. The N88D and L90M protease mutations were detected in $36 \%$ and $21 \%$ of genotyping samples, in 25\% and 20\% of RNA-OLA samples, and in $42 \%$ and $44 \%$ of DNA-OLAs, respectively.

Children who were previously exposed to short-term antivirals showed significantly higher numbers of resistance mutations detected by DNA-OLA ( $\mathrm{p}=0.01$ by Wilcoxon rank sum (WRS) test), but not by RNA-OLA ( $\mathrm{p}=0.26$; WRS test) or genotyping ( $\mathrm{p}=0.18$; WRS test) at the time of cross-sectional analysis. Virologic failure was strongly associated with the number of resistance mutations detected by DNA-OLA ( $\mathrm{p}<0.001$; WRS test).

The detection of the $\mathrm{M} 184 \mathrm{~V}$ reverse transcriptase mutation (indicating 3TC resistance) by any of the three methods (genotyping, RNA-OLA or DNA-OLA) was significantly more frequent in patients with virologic failure $\left(\mathrm{p}=0.07^{\mathrm{b}}, \mathrm{p}<0.05^{\mathrm{c}}\right.$ and $\left.\mathrm{p}<0.001^{\mathrm{c}}\right)$. Also, the mutations N88D and L90M (NFV resistance) were more frequently detected by DNA-OLA in patients with virologic failure ( $\mathrm{p}<0.001$ and $\mathrm{p}<0.05$, respectively; WRS test). The protease mutation D30N was not detected more commonly in cases of virologic failure (by any of the assays used), neither were TAMs selected differentially in failing vs. non-failing patients.

Detection of the M184V, N88D and L90M substitutions by RNA OLA was highly sensitive for virologic failure (sensitivity: 0.93, 1.0 and 1.0; binary classification test). The ability to obtain positive results with the RNA OLA, along with the detection of mutations M184V, N88D and L90M, may thus suggest virologic failure in this cohort of patients.

The detection of the same mutations (M184V, N88D and L90M) by DNA-OLA yielded a slightly lower sensitivity of $0.86,0.9$ and 0.75 for virologic failure, but the assay could be performed in almost all patient samples (regardless of virologic success or failure) indicating that virologic failure may indeed be attributed to resistance development at these three residues (these specific mutations appear significantly more frequently in failing patients, see Table 2).

\section{Relative sensitivities and specificities of the DNA- and RNA-OLA}

We evaluated the DNA-OLA and RNA-OLA relative to each other in terms of a binary classification test: The DNA-OLA yielded a sensitivity of $59 \%$ relative to the RNA-OLA. Its relative specificity was $96 \%$. Reversely, the 
sensitivity of the RNA-OLA relative to the DNA-OLA was $86 \%$, whereas its specificity was $88 \%$. (Table 3 )

\section{Discussion}

There are two important aspects in this patient cohort, characteristic of ART cohorts in resource-limited settings: a) all patients received the same first-line antiretroviral regimen and b) patients, on average, were in advanced stages of HIV/AIDS when starting their first antiretroviral regimen [35]. When antiretroviral therapy was first introduced in Peru, uniform criteria were established by the MINSA to ensure the allocation of resources and medication to those most in need. This first cohort of patients at the largest children's hospital in Peru suddenly became eligible for therapy at a time when many had already progressed to disease stages beyond the eligibility threshold.

The effect of delayed access to ART in this first cohort becomes evident in comparison to a recent study observing the transmission of resistant virus in a much younger cohort of neonates and children with timely access to pMTCT and ART in Peru, revealing a predominance of NNRTI mutations, whereas mutations conferring high-level resistance to ARV were still found to be rare [18]. This observation is unlikely an effect of age. Even though our cohort started treatment after the disease had progressed significantly, age by itself was not associated with an advanced clinical stage at enrollment. To the contrary, young age (thus earlier treatment initiation) seemed to favor virologic failure. This may also be due to a survivor effect, i.e. slower progression in those patients who had already survived the first years after MTCT.

Chances of virologic failure were high in this first pediatric cohort gaining access to ART in Peru in 2002/ 3 , with $\sim 44 \%$ showing virologic failure after the first year of ART, $53 \%$ after two years. The majority of children were in poor health, as evidenced by malnutrition $93 \%$ of children below the reference weight for the respective age group [33]) and a high prevalence of opportunistic infections. Of note, $43 \%$ showed AIDS-defining conditions and $17 \%$ co-infections with active tuberculosis. Immunologically, $67 \%$ of the children had already r.eached the immunologic $\mathrm{CDC}$ category 3 (corresponding to an
Table 3 Detection of Resistance Mutations with DNA-OLA vs. RNA-OLA

\begin{tabular}{lccc}
\hline & DNA+ & DNA- & Sum \\
\hline RNA + & 36 & 25 & 61 \\
RNA- & 6 & 278 & 184 \\
Sum & 42 & 203 &
\end{tabular}

Table 3: Comparison of DNA-OLA and RNA-OLA. The field 'DNA+/RNA+' denotes the number of resistance mutations positively detected by both DNAOLA and RNA-OLA, whereas the field 'DNA-/RNAt' denotes the number of resistance mutations where the DNA-OLA yielded a negative result and the RNA-OLA yielded a positive result.

adult CD4 levels of $<200$ cells $/ \mu \mathrm{L}$ ) prior to gaining access to structured ART.

Immunologic classification at baseline was very predictive for virologic failure. In agreement with studies in industrialized countries [36,37], these findings indicate that the percentage of CD4 cells in children with HIV/ AIDS (i.e. the immunologic category) could be used to guide treatment initiation. In fact, the immunologic classification may be more valuable for the decision of ART initiation than relying on DNA-PCR results alone [38].

Despite relatively high rates of virologic failure in this cohort, both immunological and clinical conditions improved during ART, in particular throughout the first and second years of treatment. Thereafter little additional improvement was achieved. Overall, from the time of initiation of ART up until the time of the cohort assessment, 57\% had showed marked improvement with respect to their clinical status (as measured by CDC category/visit), whereas $35 \%$ were unchanged clinically, and only $8 \%$ showed disease progression. With respect to the immunologic CDC-scores, $76 \%$ had improved, $22 \%$ had experienced no change, and $2 \%$ showed a decline in CD4 counts.

For improved visualization of the overall development of treatment cohorts during ART, we summarized the clinical and immunological response to therapy in an innovative fashion using a Clinical Course Integrated Display (CCID) with 3-by-4 tables based on the revised CDC clinical and immunological categories [27]. Here, we applied the CDC scores as a flexible tool to examine the cohort on a yearly basis, allowing for CDC scores to improve or deteriorate, according to the CD4 counts and reported clinical symptoms. Using this simple

Table 2 Frequency of Mutations Detected by Different Assays

\begin{tabular}{lccccccccc}
\hline & M184V & TAM & $\mathbf{n}$ & Virol. Failure & D30N & N88D & L90M & n & Virol. Failure \\
\hline RNA Genotyping & $\mathbf{8 0} \%^{*}$ & $50 \%$ & 10 & $70 \%$ & $43 \%$ & $36 \%$ & $21 \%$ & 14 & $70 \%$ \\
RNA-OLA & $\mathbf{7 4} \%^{* *}$ & $47 \%{ }^{3}$ & 19 & $84 \%$ & $0 \%$ & $25 \%$ & $20 \%$ & 20 & $80 \%$ \\
DNA-OLA & $\mathbf{4 7} \%^{* * *}$ & $42 \%{ }^{3}$ & 45 & $53 \%$ & $2 \%$ & $\mathbf{4 2} \%^{* * *}$ & $\mathbf{4 4}^{* *}$ & 45 & $53 \%$ \\
\hline
\end{tabular}

Table 2: Frequency of mutations detected by RNA genotyping, RNA-OLA and DNA-OLA.

*associated with virologic failure $(p<0.1)$

** strongly associated with virologic failure $(p<0.05)$,

${ }^{* * *}$ very strong association with virologic failure $(p<0.001)$

${ }^{3}$ only T215F and T215Y. 
system in cross-sectional analyses and surveillance programs, rates of disease progression (Figure 3) may be computed for different cohorts allowing the comparison of treatment strategies in terms of their clinical and immunologic effects in a given population. This system may be applicable to similar cohort studies in developed and developing countries alike, especially in conjunction with cross-sectional analyses of antiretroviral drug resistance.

Previous exposure to (often incomplete) ART was significantly associated with virologic failure, indicating that short courses of unsupervised ART prior to the initiation of coordinated long-term treatment programs may be counterproductive as they may lead to the rapid development of drug resistance. Archived drug resistance mutations, acquired during previous exposures to antiretrovirals and still present in the PBMC compartment may be detected reliably by DNA OLA.

Exposure of the newborn to post-natal pMTCT with AZT did not increase the likelihood of subsequent virologic failure, neither did maternal exposure to pMTCT with AZT +/- NVP. There are three possible explanations why pMTCT did not affect subsequent treatment success:

a) The pMTCT did not lead to a transmission/selection and "archivation" of drug resistance,

b) Although drug resistance against the pMTCT regimen (i.e. AZT +/- NVP) developed and was archived, it did not impede the success of subsequent triple-drug ART consisting of AZT + 3TC + NFV.

c) Drug resistance did not persist until the initiation of ART.

In fact, in only one child (P028T) we detected archived drug resistance by DNA OLA (mutation 215Y; AZT resistance) at the time of cross-sectional resistance testing. This child (P028T) did not encounter virologic failure (hinting towards scenario b).

Drug resistance in the context of pMTCT may emergeor be transmitted - by two possible mechanisms:

(i) Drug resistant virus is selected in the mother and passed on to the child (e.g. during birth or breastfeeding).

(ii) The newborn is infected with susceptible virus and subsequently selects drug resistant virus, e.g. during ARV exposure.

Ad (i): When a single dose of antivital medication for maternal pMTCT is administered at the onset of labor, it is rather unlikely that drug resistant virus is passed on to the child. Although the pMTCT regimen may induce a selective pressure on the maternal virus, there is hardly enough time for this virus to be selected to sufficient numbers to be transmitted during birth, see also [39].
However, drug resistant virus may, with some probability, be transmitted during subsequent breastfeeding [39].

Newborns P019T, P020T and P028T were not breastfed and their mothers received a single dose of AZT +/- NVP shortly before birth. However, these newborns received $6 \mathrm{mg} /$ day (P019T, P020T) or $28 \mathrm{mg} /$ day (P028T) of postnatal AZT. As explained above, postnatal AZT administered to P028T may explain the archiving of AZT resistance in the child's PBMC DNA (case ii). However, this did not lead to subsequent therapeutic failure (case b).

The mothers of newborns P002T, P003T, P027T and P046T were breastfeeding. They received extended AZT for periods shorter than the actual duration of breastfeeding. None of these children (P002T, P003T, P027T and P046T) showed evidence of archived AZT resistance based on DNA-OLA at the time of cross-sectional assessment. These children could have either been infected with susceptible virus during labour, or during breastfeeding (after cessation of extended maternal AZT), or else resistance may not have persisted until treatment initiation or until the DNA OLA was performed.

A potential weakness of a cross-sectional study design is that clinical and laboratory data from the beginning of ART up until the date of cross-sectional analysis had to be extracted from medical records and parent/patient interviews. Adherence data using the PACTG questionnaire are always self-reported. This study design does not allow for detailed cause-effect analyses, prospective surveillance and follow-up visits, or the assessment of mortality data. The cross-sectional analysis however does reflect the realworld effectiveness of a medical intervention in a lowresource setting, which often includes patients who would not typically be able to participate in controlled clinical trials. The focus of this study was the assessment of the usefulness of cross-sectional resistance testing using the DNA versus RNA OLA.

The DNA OLA may be particularly useful for the purposes of population-based surveillance in low resource settings where genotyping tests may not be readily available. The DNA-OLA was very indicative for the presence of resistance (high specificity, low false positive rate), but less indicative for the absence of resistance (low sensitivity, high false negative rate) in comparison to the RNA OLA. To the contrary, the RNA-OLA was more useful to determine the absence rather than the presence of drug resistance. Therefore, DNA-OLA can be used to rule-in resistance, whereas RNA-OLA may be used to rule-out resistance.

The detection of the resistance mutations $\mathrm{M} 184 \mathrm{~V}$, N88D and L90M by DNA-OLA was highly sensitive for virologic failure in this cohort treated with lamivudineazidothymidine-nelfinavir as first-line therapy. The analysis of archived HIV-DNA resistance in PBMC provided useful results in most patients, even if virologic failure was not (yet) evident. The DNA-OLA may detect resistance 
mutations that have been acquired during previous exposure to erratic short-term ART, still present in the lymphocyte compartment. This may occur in low-resource settings before antivirals become universally available, when patients and their families are restricted to temporary access to limited, often insufficient amounts of antiviral medications. Turnover rates within the lymphocyte compartment may however be too low for the early detection of antiretroviral drug resistance during therapy (i.e. in time before viral failure becomes apparent).

A possible strategy for the improvement of ART in resource-poor settings (where genotyping is often not available) could be to use the DNA-OLA as a baseline screening tool before starting therapy. This could be combined with the use of RNA-OLA in those patients experiencing virologic failure. Notably, a positive RNA OLA at positions M184V, N88D or L80M was highly sensitive for virologic failure (sensitivity: $0.93,1.0$ and 1.0, respectively). Therefore, drug resistance monitoring at key residues using RNA OLA in patients experiencing virologic failure may be particularly useful as an economical indicator of drug resistance and could suggest a treatment change.

Success rates could likely be improved even further if treatment was initiated at higher CD4 counts, in line with recent revisions of the treatment guidelines in industrialized countries (initiation of treatment at an adult CD4 count of $350 \mathrm{cell} / \mu \mathrm{L})[36,37]$. This is in agreement with recent reports from other cohorts in Latin America. A recent cross-sectional analysis and evaluation of clinical outcomes of ART in Latin America showed that nearly half of the patients were so-called "late testers/presenters". Evaluations of outcomes with ART in Latin American children revealed a higher incidence of opportunistic infections when compared to US cohorts (such as PACTG 129C) $[36,37]$.

While consensus RNA genotyping (if available) will likely remain the mainstay of individualized resistance testing during ongoing antiretroviral therapy, the applicability of the OLA in population-based surveillance remains to be fully assessed in larger cohorts, including cost-effectiveness analyses and assessments of the personnel and training required for either method. At the time of the study, genotyping was not available. In recent years, capacities for monitoring drug resistance have been expanded at the Peruvian INS including sequencing facilities and an e-health driven, web-based laboratory information system $[40,41]$. The national ART program was expanded in 2004 to include larger parts of the population living with HIV/AIDS, including infants in earlier stages of HIV infection [41-43].

Our data emphasize the need for timely antiretroviral treatment initiation and early HIV testing to contribute to this aim [5,12,35,44]. For children undergoing therapy, regular follow-up visits with viral load and resistance testing and concrete measures to monitor and improve adherence (using PDA's, cellphone reminders and other e-health features) may be a key to success of ART in Latin America and beyond [45-52].

\section{Conclusions}

1. HIV drug resistance was the major factor contributing to virologic failure of antiretroviral therapy in this cohort of children with delayed access to structured ART in Lima, Peru.

2. In most instances, virologic failure occurred early in the course of treatment and commonly after previous exposure to unsupervised ART, but not in relation to pMTCT.

3. The DNA OLA method detected antiretroviral resistance at key positions independently of virologic failure in the form of integrated DNA (in PBMC), whereas the RNA OLA detected antiviral resistance in viral RNA (in plasma) only after virologic failure. Antiviral resistance was more readily detected by OLA than by RNA consensus genotyping (from dried blood spots).

4. The DNA-OLA could be used prior to treatment initiation to rule-out archived drug resistance to standard regimens, in particular when previous exposure to antiretrovirals is anticipated. The RNAOLA could be used to guide the choice of secondline antiretrovirals in patients switching ART regimens after experiencing virologic failure.

\section{Endnotes}

a confirmed by DNA-PCR/viral load at 6 months, or by ELISA at/after 18 months or AIDS-defining diagnosis

b Fisher's exact test

${ }^{c} x^{2}$ test

\section{Additional files}

Additional file 1: Individual viral load dynamics in children after treatment initiation, stratified by responders (black solid dots) and children who experienced virologic failure (red squares).

Additional file 2: Sequencing Data. Table with the raw viral sequencing data from dried blood spots.

Additional file 3: OLA Data. Table with the raw OLA data from plasma (RNA-OLA) and PBMCS (DNA-OLA).

\section{Abbreviations}

INS: Instituto Nacional del Salud (Peruvian National Institutes of Health); IESN: Instituto Especializado de Salud del Niño; PRISMA: Asociación Benéfica Proyectos en Informática, Salud, Medicina y Agricultura; MINSA: Ministerio de Salud del Peru; PACTG: Pediatric AIDS Clinical Trials Group; ART: Antiretroviral Therapy; MTCT: Mother-to-child transmission; pMTCT: Prevention of motherto-child transmission; AZT: Azidotymidine; 3TC: Lamivudine (LMV); NFV: Nelfinavir; NRTI: Nucleoside-analogue Reverse Transcriptase Inhibitors; NNRTI: Non-nucleoside-analogue Reverse Transcriptase Inhibitors; PI: Protease Inhibitor; OLA: Oligonucleotide Ligation Assay; PCR: Polymerase Chain 
Reaction; RNA: Ribonucleic Acid; DNA: Desoxyribonucleic Acid; WHO: World Health Organization; HIV: Human immunodeficiency virus; AIDS: Acquired Immunodeficiency Syndrome.

\section{Competing interest}

All authors declare no competing interests.

\section{Authors' contributions}

Study concept and design: BAR, RAO, RVD, DKK. Acquisition of data: BAR, GSC, MEC, LK. Laboratory Analyses: BAR, PC; AMA, JER, DKK. Analysis and interpretation of data: MVK, BAR. Drafting of the manuscript: BAR, MVK. Critical revision of the manuscript for intellectual content: DKK, RAO, RVD, AMA, GSC, PC. Statistical analysis: MVK. All authors read and approved the manuscript.

\section{Acknowledgements}

The authors kindly thank the staff of the non-governmental organization P.R. I.S.M.A in Lima, Peru, for their help with the data entry and the abstraction of medical records, as well as with the preparation, shipping and handling of blood samples. They thank Prof. Robert Gilman, Johns Hopkins University/ Bloomberg School of Public Health, the INS and the INSN for accommodating and supporting the study project in Lima. They also thank Nedra Lacour for the viral load measurements and RNA extraction at the Tulane PACTU laboratory and Prof. Lisa Frenkel, University of Washington, for her advice with respect to the OLA testing. All authors declare no competing interests.

\section{Funding}

The authors have no conflicts of interest to declare. This pro bono project was sponsored by the Department of Pediatrics, Division of Infectious Diseases at Tulane University Health Sciences Center in New Orleans, Louisiana. The OLA PRC Primers and Protocol (open-source) provided by the US National Institutes of Health. Max von Kleist acknowledges funding from the DFG research center MATHEON provided through project A21 "Modeling, Simulation and Therapy Optimization for Infectious Diseases".

\section{Author details}

${ }^{1}$ Department of Pediatrics, Division of Pneumonology-Immunology, Charité University Medical Center, Berlin, Germany. ${ }^{2}$ Department of Pediatrics, Division of Infectious Diseases, Tulane University Health Sciences Center, New Orleans, Louisiana, USA. 'Department of Mathematics and Computer Science, Free University Berlin, Berlin, Germany. ${ }^{4}$ Infectious Diseases Service, Instituto Nacional de Salud del Niño Lima, Peru. ${ }^{5}$ Executive Directorate of Research, National Institute of Health, Lima, Peru. ${ }^{6}$ Asociación Benéfica PRISMA, Lima, Peru. ${ }^{7}$ Department of Microbiology, Immunology \& Parasitology, Louisiana State University Health Sciences Center, New Orleans, Louisiana, USA. ${ }^{8}$ Center for AIDS Research, Stanford University, Stanford, Palo Alto, USA. ${ }^{9}$ Department of Pediatrics, Universidad Peruana Cayetano Heredia, Lima, Peru.

Received: 2 June 2012 Accepted: 21 December 2012

Published: 2 January 2013

\section{References}

1. UNAIDS: Report on the Global AIDS Epidemic - Executive Summary. Geneva, Switzerland: UNAIDS - Joint United Nations Programme on HIV/AIDS: Edited by HIV/AIDS U-JUNPO; 2004:1-22.

2. Hainaut M, Ducarme M, Schandene L, Peltier CA, Marissens D, Zissis G, Mascart F, Levy J: Age-related immune reconstitution during highly active antiretroviral therapy in human immunodeficiency virus type 1-infected children. Pediatr Infect Dis J 2003, 22(1):62-69.

3. Curioso WH, Kepka D, Cabello R, Segura P, Kurth AE: Understanding the facilitators and barriers of antiretroviral adherence in Peru: a qualitative study. BMC Public Health 2010, 10:13.

4. Franke MF, Murray MB, Munoz M, Hernandez-Diaz S, Sebastian JL, Atwood S, Caldas A, Bayona J, Shin SS: Food Insufficiency is a Risk Factor for Suboptimal Antiretroviral Therapy Adherence among HIV-Infected Adults in Urban Peru. AIDS Behav 2011, 15(7):1483-1489.

5. Franke MF, Munoz M, Finnegan K, Zeladita J, Sebastian JL, Bayona JN, Shin SS: Validation and abbreviation of an HIV stigma scale in an adult spanish-speaking population in urban Peru. AIDS Behav 2010, 14(1):189-199.

6. Esteban PM, Thahn TG, Bravo JF, Roca LK, Quispe NM, Montano SM, Zunt JR: Malnutrition associated with increased risk of peripheral neuropathy in Peruvian children with HIV infection. J Acquir Immune Defic Syndr 2009, 52(5):656-658.

7. Willig $\mathrm{JH}$, Echevarria J, Westfall $A O$, Iglesias $D$, Henostroza $G$, Seas C, Mugavero MJ, Allison J, Paz J, Hernandez F, et al: Durability of initial antiretroviral therapy in a resource-constrained setting and the potential need for zidovudine weight-based dosing. J Acquir Immune Defic Syndr 2010, 53(2):215-221

8. Shin S, Munoz M, Zeladita J, Slavin S, Caldas A, Sanchez E, Callacna M, Rojas C, Arevalo J, Sebastian JL, et al: How does directly observed therapy work? The mechanisms and impact of a comprehensive directly observed therapy intervention of highly active antiretroviral therapy in Peru. Health Soc Care Community 2011, 19(3):261-271.

9. Reynolds NR, Testa MA, Marc LG, Chesney MA, Neidig JL, Smith SR, Vella S, Robbins GK: Factors influencing medication adherence beliefs and selfefficacy in persons naive to antiretroviral therapy: a multicenter, cross-sectional study. AIDS Behav 2004, 8(2):141-150.

10. Pontali E, Feasi M, Toscanini F, Bassetti M, De Gol P, Nuzzolese A, Bassetti D: Adherence to combination antiretroviral treatment in children. HIV Clin Trials 2001, 2(6):466-473.

11. Cesar C, Shepherd BE, Krolewiecki AJ, Fink VI, Schechter M, Tuboi SH, Wolff M, Pape JW, Leger P, Padgett D, et al: Rates and reasons for early change of first HAART in HIV-1-infected patients in 7 sites throughout the Caribbean and Latin America. PLoS One 2010, 5(6):e10490.

12. Munoz M, Bayona J, Sanchez E, Arevalo J, Sebastian JL, Arteaga F, Guerra D, Zeladita J, Espiritu B, Wong M, et al: Matching Social Support to Individual Needs: A Community-Based Intervention to Improve HIV Treatment Adherence in a Resource-Poor Setting. AIDS Behav 2011, 15(7):1454-1464.

13. Eshleman SH, Mracna M, Guay LA, Deseyve M, Cunningham S, Mirochnick M, Musoke P, Fleming T: Glenn Fowler M, Mofenson LM et al:: Selection and fading of resistance mutations in women and infants receiving nevirapine to prevent HIV-1 vertical transmission (HIVNET 012). AIDS 2001, 15(15):1951-1957.

14. Wang ME, Castillo ME, Montano SM, Zunt JR: Immune reconstitution inflammatory syndrome in human immunodeficiency virus-infected children in Peru. Pediatr Infect Dis J 2009, 28(10):900-903.

15. MINSA: Aprobación de la directiva. In. Lima, Peru: Ministerio de Salud del Peru (MINSA): Tratamiento Antiretroviral en los niños infectados por el VIH; 2002.

16. MINSA: Guía Nacional de Manejo del Niño infectado por el VIH.: In. Lima: Ministerio de Salud del Peru (MINSA); 1999.

17. DIRECTIVA No. 020 - 2003-MINSA/DGSP-DEAIS-V.01: 2003 [http://www sgcnnavih.cepesju.org/Normativas/DIRECTIVA_020-2003-MINSA_DGSPDEAIS-V.01.pdf]

18. Soria J, Bull M, Mitchell C, Rosa AL, Dross S, Kraft K, Coombs R, Ticona E, Frenkel L: Transmitted HIV Resistance to First-Line Antiretroviral Therapy in Lima. AIDS Res Hum Retroviruses 2012, 28(4):333-8.

19. Ellis GM, Mahalanabis M, Beck IA, Pepper G, Wright A, Hamilton S, Holte S, Naugler WE, Pawluk DM, Li CC, et al: Comparison of oligonucleotide ligation assay and consensus sequencing for detection of drug-resistant mutants of human immunodeficiency virus type 1 in peripheral blood mononuclear cells and plasma. J Clin Microbiol 2004, 42(8):3670-3674.

20. Schinazi RF, Schlueter-Wirtz S, Stuyver L: Early detection of mixed mutations selected by antiretroviral agents in HIV-infected primary human lymphocytes. Antivir Chem Chemother 2001, 12(Suppl 1):61-65.

21. Frenkel LM, Wagner LE 2nd, Atwood SM, Cummins TJ, Dewhurst S: Specific, sensitive, and rapid assay for human immunodeficiency virus type $1 \mathrm{pol}$ mutations associated with resistance to, and didanosine. J Clin Microbiol 1995, 33(2):342-347.

22. Cassol SA, Read S, Weniger BG, Pilon R, Leung B, Mo T: Diagnosis and Direct Automated Sequencing of HIV-1 From Dried Blood Spots (DBS) Collected on Filter Paper. Methods Mol Med 1999, 17:125-138.

23. Sherman GG, Stevens G, Jones SA, Horsfield P, Stevens WS: Dried blood spots improve access to HIV diagnosis and care for infants in lowresource settings. J Acquir Immune Defic Syndr 2005, 38(5):615-617.

24. Youngpairoj AS, Masciotra S, Garrido C, Zahonero N, de Mendoza C, GarciaLerma JG: HIV-1 drug resistance genotyping from dried blood spots stored for 1 year at 4 degrees C. J Antimicrob Chemother 2008, 61(6):1217-1220. 
25. Mitchell C, Jennings C, Brambilla D, Aldrovandi G, Amedee AM, Beck I, Bremer JW, Coombs R, Decker D, Fiscus S, et al: Diminished human immunodeficiency virus type 1 DNA yield from dried blood spots after storage in a humid incubator at 37 degrees $C$ compared to -20 degrees C. J Clin Microbiol 2008, 46(9):2945-2949.

26. Mitchell C, Kraft K, Peterson D, Frenkel L: Cross-contamination during processing of dried blood spots used for rapid diagnosis of HIV-1 infection of infants is rare and avoidable. J Virol Methods 2010, 163(2):489-491.

27. CDC: Revised Classification System for Human Immunodeficiency Virus Infection in Children Less Than 13 Years of Age. MMWR 1994, 43(12):1-10.

28. Farley JJ, Montepiedra G, Storm D, Sirois PA, Malee K, Garvie P, Kammerer B, Naar-King S, Nichols S: Assessment of adherence to antiretroviral therapy in perinatally HIV-infected children and youth using self-report measures and pill count. J Dev Behav Pediatr 2008, 29(5):377-384.

29. Naar-King S, Montepiedra G, Nichols S, Farley J, Garvie PA, Kammerer B, Malee K, Sirois PA, Storm D: Allocation of family responsibility for illness management in pediatric HIV. J Pediatr Psychol 2009, 34(2):187-194.

30. Henning TR, Lacour N, Amedee AM: Efficient methodologies for sensitive HIV-1 RNA quantitation from plasma and vaginal secretions. J Clin Virol 2009, 46(4):309-313.

31. Beck IA, Mahalanabis M, Pepper G, Wright A, Hamilton S, Langston E, Frenkel LM: Rapid and sensitive oligonucleotide ligation assay for detection of mutations in human immunodeficiency virus type 1 associated with high-level resistance to protease inhibitors. J Clin Microbiol 2002, 40(4):1413-1419.

32. Shafer RW, Hertogs K, Zolopa AR, Warford A, Bloor S, Betts BJ, Merigan TC, Harrigan $\mathrm{R}$, Larder $B A$ : High degree of interlaboratory reproducibility of human immunodeficiency virus type 1 protease and reverse transcriptase sequencing of plasma samples from heavily treated patients. J Clin Microbiol 2001, 39(4):1522-1529.

33. Child Growth Standards: [http://www.who.int/childgrowth/standards/ weight_for_age/en/index.html]

34. Johnson VA, Calvez V, Gunthard HF, Paredes R, Pillay D, Shafer R, Wensing AM, Richman DD: 2011 update of the drug resistance mutations in HIV-1. Top Antivir Med 2011, 19(4):156-164.

35. Crabtree-Ramirez B, Caro-Vega Y, Shepherd BE, Wehbe F, Cesar C, Cortes C, Padgett D, Koenig S, Gotuzzo E, Cahn P, et al: Cross-sectional analysis of late HAART initiation in Latin America and the Caribbean: late testers and late presenters. PLoS One 2011, 6(5):e20272

36. Alarcon JO, Freimanis-Hance L, Krauss M, Reyes MF, Cardoso CA, Mussi-Pinhata MM, Cardoso E, Alarcon JO, Freimanis-Hance L, Krauss M, Reyes MF, Cardoso CA, Mussi-Pinhata MM, Cardoso E, Alarcon JO, Freimanis-Hance L, Krauss M, Reyes MF, Cardoso CA, Mussi-Pinhata MM, Cardoso E: Opportunistic and other infections in HIV-infected Children in Latin America compared to a similar cohort in the United States. AIDS Res Hum Retroviruses 2012, 28(3):282-8

37. Patel K, Hernan MA, Williams PL, Seeger JD, McIntosh K, Dyke RB, Seage GR 3rd: Long-term effects of highly active antiretroviral therapy on CD4+ cell evolution among children and adolescents infected with HIV: 5 years and counting. Clin Infect Dis 2008, 46(11):1751-1760.

38. Feucht UD, Forsyth B, Kruger M: False-positive HIV DNA PCR testing of infants: Implications in a changing epidemic. S Afr Med J 2012, 102(3):149-152.

39. Frank M, von Kleist M, Kunz A, Harms G, Schutte C, Kloft C: Quantifying the impact of nevirapine-based prophylaxis strategies to prevent mother-tochild transmission of HIV-1: a combined pharmacokinetic, pharmacodynamic, and viral dynamic analysis to predict clinical outcomes. Antimicrobial agents and chemotherapy 2011, 55(12):5529-5540.

40. Garcia PJ, Vargas JH, Caballero NP, Calle VJ, Bayer AM: An e-health driven laboratory information system to support HIV treatment in Peru: E-quity for laboratory personnel, health providers and people living with HIV. BMC Med Inform Decis Mak 2009, 9:50

41. MINSA: A Step Forward in the Flght Against AIDS. In. Lima: Ministerio de Salud del Peru (MINSA): The first two years of universal access to antiretroviral treatment in Peru; 2006.

42. Aldridge RW, Iglesias D, Caceres CF, Miranda JJ: Determining a cost effective intervention response to HIV/AIDS in Peru. BMC Public Health 2009, 9:352.

43. Tuboi SH, Schechter M, McGowan CC, Cesar C, Krolewiecki A, Cahn P, Wolff M, Pape JW, Padgett D, Madero JS, et al: Mortality during the first year of potent antiretroviral therapy in HIV-1-infected patients in 7 sites throughout Latin America and the Caribbean. J Acquir Immune Defic Syndr 2009, 51(5):615-623.

44. Clark JL, Long CM, Giron JM, Cuadros JA, Caceres CF, Coates TJ, Klausner JD: Partner notification for sexually transmitted diseases in Peru: knowledge, attitudes, and practices in a high-risk community. Sex Transm Dis 2007 34(5):309-313.

45. Furin JJ, Behforouz HL, Shin SS, Mukherjee JS, Bayona J, Farmer PE, Kim JY, Keshavjee S: Expanding global HIV treatment: case studies from the field. Ann N Y Acad Sci 2008, 1136:12-20.

46. Curioso $\mathrm{WH}$, Kurth $\mathrm{AE}$ : Access, use and perceptions regarding Internet, cell phones and PDAs as a means for health promotion for people living with HIV in Peru. BMC Med Inform Decis Mak 2007, 7:24.

47. Bastos Fl, Caceres C, Galvao J, Veras MA, Castilho EA: AIDS in Latin America: assessing the current status of the epidemic and the ongoing response. Int J Epidemiol 2008, 37(4):729-737.

48. Curioso WH, Kurth AE, Cabello R, Segura P, Berry DL: Usability evaluation of Personal Digital Assistants (PDAs) to support HIV treatment adherence and safer sex behavior in Peru. AMIA Annu Symp Proc 2008, 918.

49. Kurth $A E$, Curioso WH, Ngugi E, McClelland L, Segura P, Cabello R, Berry DL: Personal digital assistants for HIV treatment adherence, safer sex behavior support, and provider training in resource-constrained settings. AMIA Annu Symp Proc 2007, 1018.

50. Lopez De Castilla D, Verdonck K, Otero L, Iglesias D, Echevarria J, Lut L, Gotuzzo E, Seas C: Predictors of CD4+ cell count response and of adverse outcome among HIV-infected patients receiving highly active antiretroviral therapy in a public hospital in Peru. Int J Infect Dis 2008, 12(3):325-331.

51. Corey DM, Kim HW, Salazar R, Illescas R, Villena J, Gutierrez L, Sanchez J, Tabet SR: Brief report: effectiveness of combination antiretroviral therapy on survival and opportunistic infections in a developing world setting: an observational cohort study. J Acquir Immune Defic Syndr 2007, 44(4):451-455

52. Cohen J: HIV/AIDS: Latin America \& Caribbean. Peru: universal access: more goal than reality. Science 2006, 313(5786):489.

doi:10.1186/1471-2334-13-1

Cite this article as: Rath et al:: Antiviral Resistance and Correlates of Virologic Failure in the first Cohort of HIV-Infected Children Gaining Access to Structured Antiretroviral Therapy in Lima, Peru: A CrossSectional Analysis. BMC Infectious Diseases 2013 13:1.

\section{Submit your next manuscript to BioMed Central and take full advantage of:}

- Convenient online submission

- Thorough peer review

- No space constraints or color figure charges

- Immediate publication on acceptance

- Inclusion in PubMed, CAS, Scopus and Google Scholar

- Research which is freely available for redistribution 